\title{
SYNTHESIS OF MONODISPERSED MAGNETITE PARTICLES FROM DIFFERENT ORGANOMETALLIC PRECURSORS
}

\author{
A.G. Roca, M. P. Morales and C. J. Serna \\ Instituto de Ciencia de Materiales de Madrid,CSIC, c/ Sor Juana Inés de la Cruz 3, Madrid, \\ Spain \\ alexgr@icmm.csic.es
}

There is increasing optimism that nanotechnology applied to medicine will bring significant advances in diagnosis, prevention and treatment of disease. Many aspects of nanomedicine rely on progress in nanomaterials research. This is the case for the minimization of magnetic nanoparticle polydispersity and heterogeneity, which is essential for their use in the construction of nanopharmaceuticals [1].

Organometallic precursor-based synthesis has proved successful for the preparation of uniform nanoparticles [2]. The technique was first developed for cadmium selenide and later applied to the preparation of magnetic metal and metal oxide nanoparticles [3-5]. This method is widely used because of the ease and reproducibility of the synthesis, as well as the uniformity and high crystallinity of the particles. The method consists of the decomposition of an organometallic precursor in the presence of capping groups using organic solvents with high boiling points [2]. The capping groups, typically long chain alkyl surfactants, such as oleic acid or oleylamine, bind to the particle surface and are responsible not only for the stabilization against aggregation (steric repulsion), but also have an active role during the reaction [6]. This method has yielded markedly improved samples with good size control, narrow size distribution and excellent crystallinity of individual nanoparticles in comparison with more traditional methods [4,5]. However, absolute control over size, shape and distribution remains a challenge. Many different factors such as the nature of the precursor, the ligand and the solvent, the ligand:precursor ratio and the decomposition temperature affect the morphology of the resulting particles. These factors will be summarised in this work and an evaluation of the possible mechanisms of formation of the nanoparticles obtained from different precursors will be proposed. When $\mathrm{Fe}(\mathrm{CO})_{5}$ is used as precursor, magnetite $\left(\mathrm{Fe}_{3} \mathrm{O}_{4}\right)$ nanoparticles with sizes between 4 and $16 \mathrm{~nm}$ can be obtained in the presence of oleic acid by controlling the experimental conditions [7]. It has been shown that the carboxylic acid catalyzes the decomposition leading to decreased decomposition temperatures and, consequently as the surfactant concentration increases, smaller particles are formed [6]. $\mathrm{Fe}(\mathrm{CO})_{5}$ used as precursor in the synthesis is volatile, thermally unstable and a well-known toxic material. As alternative precursors, iron acetylacetonate and iron-oleate complexes, previously formed from an iron salt, have been used for the preparation of magnetite particles [8] (Fig. 1). Although the particles are magnetite in all cases, the size, shape and distribution of nanoparticles differ depending on the precursor and consequently the samples show different magnetic behaviour [9]. A different mechanism of formation of the nanoparticles is expected and related to the decomposition rate of the precursor. 


\section{References:}

[1] European Science Fondation (2005) ESF Scientific Forward Look on Nanomedicine,

[2] Tartaj P., Morales M. P., Veintemillas-Verdaguer S., González-Carreño T. and C. J.

Serna, J. Phys. D; App. Phys, 36 (2003) R182.

[3] Murray C. B., Kagan C. R., Bawendi M. G., Annu. Rev. Mater. Sci. 30 (2000) 545

[4] Sun S., Zeng H., Robinson D. B., Raoux S., Rice M., Wang S. X. and Li G., J. Am.

Chem. Soc. 126 (2004) 273.

[5] Jana N. R., Chen Y. and Peng X., Chem. Mater., 16 (2004) 3931.

[6] Yin M., Willis A., Redl F., Turro N. J. and O'Brien S. P., J. Mater. Res. 19 (2004) (4) 1208

[7] Park J., Lee E., Hwang N. M., Kang M., Sung C. K., Hwang Y., Park J. G., Noh H. J., Kim J. Y., Park J. H., Hyeon T., Angewandte 44 (2005) (19) 2872

[8] Park J., An K., Hwang Y., Park J. G. , Noh H. J., Kim J. Y. , Park J. H., Hwang N. M. and Hyeon T. Nature Mat. 3 (2004) 891.

[9] Roca A. G., Morales M. P., O’Grady K. and Serna C. J., submitted for publication to Nanotechnology

\section{Figures:}
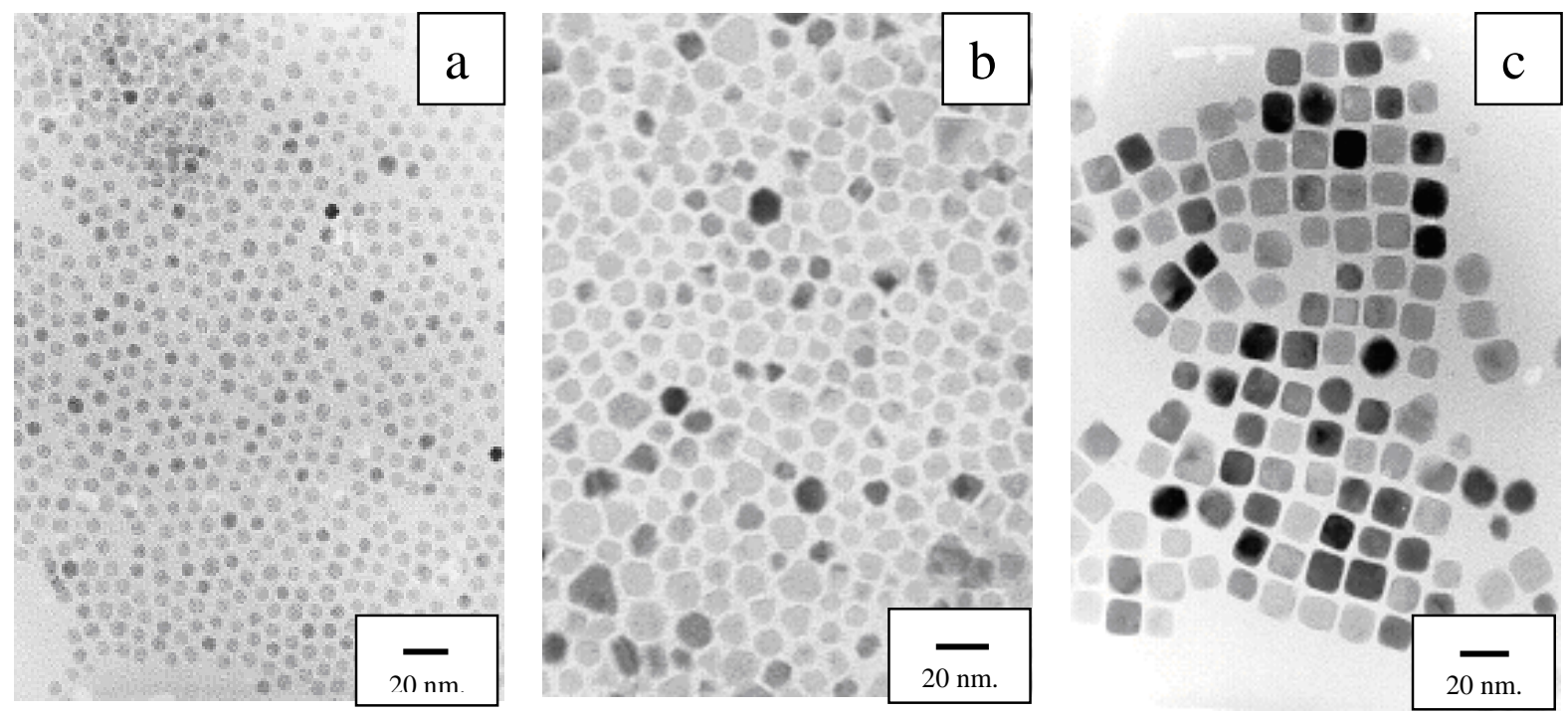

Fig. 1: Magnetite nanoparticles synthesised by decomposition of different organometallic precursors in organic solvents at high boiling temperatures and in the presence of oleic acid: a) $\mathrm{Fe}(\mathrm{CO})_{5}$; b) $\mathrm{Fe}$ acetylacetonate; and c) Fe chloride. 